\title{
THE FINITE DISPLACEMENT BEHAVIOR OF HORIZONTALLY CURVED ELASTIC I-SECTION PLATE GIRDERS UNDER BENDING
}

\author{
By Shigeru HIWATASHI* and Shigeru KURANISHI**
}

\begin{abstract}
A study of behavior of curved plate girders under bending is made, emphasizing mainly the interactions between the flange plates and the web plate. The analyses are carried out by using finite element method based on the finite displacement theory. In this paper, the behavior of curved plate girders under bending is described, such as out-of-plane displacemnent of web plate, in-plane stress distribution and corresponding effective web width, resisting moment of girders and so on. The results shows that so called vertical buckling of flange plate does not arise from loss of the bending capacity of the plate girder. Moreover discussions about the more reasonable boundary conditions of the web panel as partial structural element for analyzing curved plate girders are described.
\end{abstract}

\section{INTRODUCTION}

Concerning the buckling properties and the load carrying capacity of straight plate girders, many researches have been carried out theoretically or experimentally, and many papers have been published on this subject. One of the remarkable studies among them was made by Basler et al. ${ }^{1)}$. They indicate that the bending strength of plate girders is gorverned by both the buckling strength of a compressed flange plate and the post buckling behavior of the web plates, and propose a design method based on the ultimate strength. Hence much discussion has been presented reffering this proposals by Hasegawa et al. ${ }^{2) .3)}$ and other reseachers.

Maegawa et al.") analyzed the bending strength of horizontally curved plate girders with residual stresses using the transfer matrix method, and examined their analytical method comparing with some experimental results. But, their study did not cover the wide variety of cross section and thus failed to establish the design criteria of curved plate girders. Nakai et al. ${ }^{7)}$ calculated the horizontal buckling strength of curved I-girder bridge structures by using the elasto-plastic finite deformation theory, and showed also that the results from their theoretical analyses agree fairly well with their experimental results. Hence comes their following conclusions. If lateral and sway bracings have sufficient rigidity, then no overall lateral buckling occurs, and the collapse of the structure as a whole is led by the buckling of a flange plate between rigid supports where bracings are connected. They also proposed some design aids for cross beams, sway bracings and lateral bracings. In Ref.8), they presented experimental data of the bending strength of web plates of curved I-gieders, but there is no definite conclusion on the influence of structural parameters, such as the width-thickness ratio of a web and the size of flanges, which probably affect the behavior of

* Member of JSCE M. Eng., Associate Professor of Civil Engineering, Tohoku Gakuin University (Tagazyo, Miyagi)

** Member of JSCE Dr. Eng., Professor of Civil Engineering, Tohoku University (Sendai, Miyagi) 
curved girders. In this meaning they only check the strength of the tested girders and offered topics for further discussion.

Although many papers hi:e been published on various subjects related to curved plate gieders, such as analytical methods, experimental studies, design methods and limits of usage, very few studies were reported on the post-buckling behavior of the web plate and the interaction of the web plate and the flange plate in the finite deformation. Therefore the design proposals based on these studies lead hitherto possibly to include some guess work.

Authors ${ }^{5,6)}$ analyzed the finite displacement of the web plate of curved plate girders under bending as an isolated member from a whole structure. And some discussions are presented about loading procedure that always satisfies the compatibility with adjoining panels, the nonlinearity of compressive bending stresses produced in the web panel, the evaluation of the effective web width, the out-of-plane shearing force and moment in the connections of web plate and flange plate, and strains of web plates in the vertical direction.

The isolating technique may be useful when the basic behavior of the web plates is analyzed in finite displacement, but is not sufficient to know the mutual restraining effect of the web plate and the flange plate, or it is not possible to analyze this effect by this technique. Thereupon, in this paper, the finite displacement analysis of a panel which consists of a web plate and a upper flange and a lower flange is carried out, by emphasis on the interactions between the web plate and the flange plate, which have not been discussed so much, as well as on the difference between results obtained from the isolated web panel and the isolated flange-web panel.

\section{ANALYTICAL METHOD}

The panel analyzed here is isolated from a bisymmetrical I-section plate girder with two adjacent transverse stiffeners. Similarly to our previous paper ${ }^{5}$, the forced displacement loading method is employed here. Namely, the bending is produced by the displacements which are linear in the vertical direction and are zero on the neutral axis (this displacements are expressed by forced bending strain $\varepsilon_{0}$ divided by the panel length) and then uniform normal displacements (also expressed by compensating strain $: \varepsilon_{H}$ ) are specified to assure the state of pure bending (Fig.1). Henceforth the sum of the forced bending strain and the compensating strain is called the forced $\operatorname{strain}(\varepsilon)$. It is assumed that the panel to be analyzed has two transverse stiffeners which provide complete restraint against the out-of-plane bending of the web plate and the displacement in the longitudinal direction of the stiffener axis. Hence the boundary condition along the vertical edges of the web (i.e. loaded edges) is simple support to the direction of circumference and is rigid support against both the rotation about the longitudinal axis and the longitudinal direction of transverse stiffeners (i.e. vertical direction). Because of the symmetry of panels, the rotation about the vertical axis of the central section of the panel is restrained, and thus the analysis is carried out only for the right half of the panel. In the isolated web panel, the top and the bottom edge of the panel are free to the vertical direction and are either fixed or free for rotation about the circumference axis (indicated in the figures as Fix or S.S.), but in the isolated I-section panel the supporting condition of the edges is S.S.. The data which are shown for the panel without flanges are from to the previous paper ${ }^{5}$.

Four structural parameters used in the numerical analysis are the aspect ratio $\lambda=h / t$, the width-thickness ratio $\alpha=1 / h$, the radius of curvature $\mathrm{R}$ of the web plate and the ratio of the sectional area flange plate $\left(A_{f}\right)$ to that of web plate $\left(A_{w}\right) \beta=A_{f} / A_{w}$. In order to emphasize the influence of curvature on the behavior, the value of $\mathrm{R}$
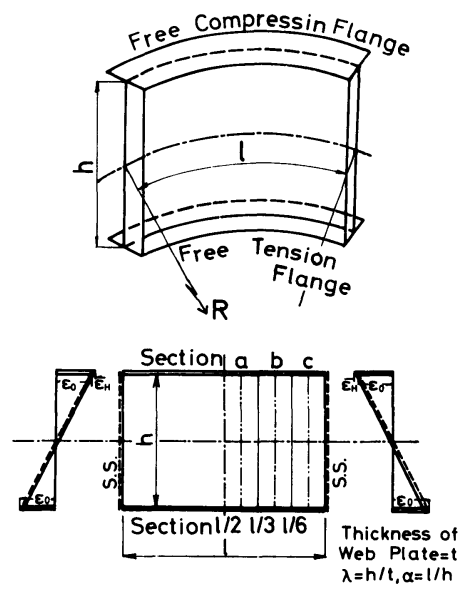

Fig. 1 Analyzed panel, names of sections and loading method. 
is mostly set $30 \mathrm{~m}$ (for $h=1.2 \mathrm{~m}$ ), but this value is changed to $60 \mathrm{~m}$ or $120 \mathrm{~m}$ when necessary. The flange plates have a varying width-thickness ratio from 14 to 20 .

The parameters used here are as follows, but some combinations are neglected.

$\lambda=150,300,400,500 \quad \alpha=0.5,2 / 3,1.5 \quad \beta=1 / 4,0.5,1.0,1.5,2.0$

Values for these parameters are chosen such that the state for bending of the curved web plates becomes severe according to results from Ref. 5) and the width-thickness ratio covers fairly high values. The range of the aspect ratio $\alpha$ is chosen around $2 / 3$ at which higher bending strength is obtained as will be discussed later on. And the ratio $\beta=A_{f} / A_{w}$ is set at values which are commonly used for practical plate girder bridges.

Assumptions and the numerical method employed here are the same as in Ref. 5), and the material is an isotropic steel of Young's modulus $E=205.8 \mathrm{GPa}$. In the finite element method with cylindrical rectangular elements, the displacement function proposed by Brebbia and Connor ${ }^{9)}$ is used. The iteration for the convergence is executed until the fluctuation of displacement caused by unbalanced forces becomes below $1.5 \%$. The one-half of the panel is divided equally into three to the circumference direction and into sixteen to the orthogonal direction. The flange element is not divided to the radial direction. The cross sections in the panel are named as shown in Fig.1.

\section{NUMERICAL RESULTS}

(1) The difference between the behavior of an isolated web panel and that of an I-girder panel

Fig. 2 shows the out-of-plane displacement of a web plate panel and an I-girder web panel at the level of $\varepsilon_{0}$ $=0.0012$ and 0.0022 , where $\beta=0$ indicates the isolated web plate panel. Structural parameters used in this analysis are given in the figure. Since the torsional rigidity of the flange plate elastically restrains the out-of-plane displacement of the web plate, it is expected that the displacement of the web plate at the I-girder panel is less than that of the isolated web plate simply supported but larger than that of the one clamped at the top and the bottom edges. However, as is shown in the figure, the displacements of I-girder panel show less value than those of the isolated web plate. In-plane bending stress $(\sigma)$ distributions over the cross section $a, b$ and $c$ of the web plate are shown in Fig.3 at the same two strain levels as the Fig.1. The nonlinearity of the distribution of stresses in the web plates simply supported is quite significant in comparison with those of the I-section girder panel and the clamped isolated web panel. The reason for this may stem from the larger compensating $\operatorname{strain}\left(\varepsilon_{H}\right)$ necessary for the isolated web plate in order to accomplish a pure bending state. Consequently the forced $\operatorname{strain}(\varepsilon)$, which is the sum of forced bending

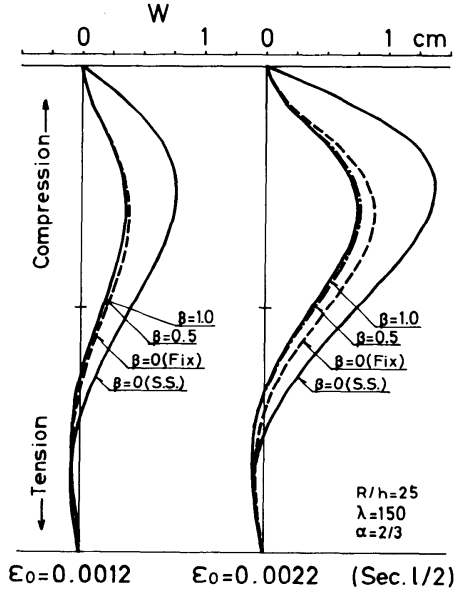

Fig. 2 Distribution of out-of-plane displacement (w).

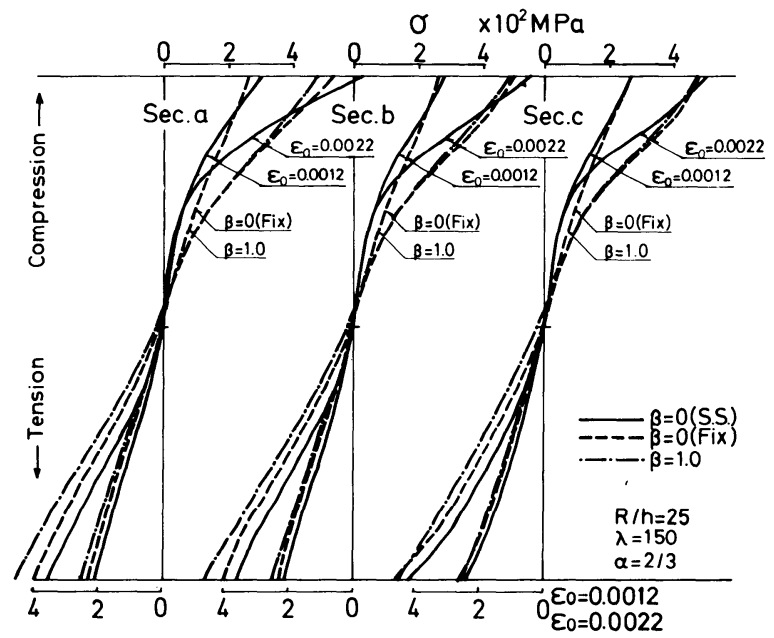

Fig. 3 Distribution of in-plane bending stress $(\sigma)$. 
Table 1 Forced bending strain $\left(\varepsilon_{0}\right)$ and compensating strain $\left(\varepsilon_{H}\right)$.

\begin{tabular}{l|l|c|c|c|c|c|c}
\hline \multicolumn{2}{l|}{ Forced Bending Strain } & \multicolumn{3}{c}{$\varepsilon_{O}=12\left(\times 10^{-4}\right)$} & \multicolumn{3}{c}{$\varepsilon_{O}=22\left(\times 10^{-4}\right)$} \\
\hline Conpensating Strain etc. & $\varepsilon_{H}$ & $\varepsilon_{O}+\varepsilon_{H}$ & $\varepsilon_{H} / \varepsilon_{O}$ & $\varepsilon_{H}$ & $\varepsilon_{O}+\varepsilon_{H}$ & $\varepsilon_{H} / \varepsilon_{O}$ \\
\hline Isolated & Upper \& Bottom Edges Simply Supported & 1.463 & 13.463 & 0.122 & 4.000 & 26.000 & 0.182 \\
Web Plate & Upper \& Bottom Edges Restrained & 0.513 & 12.513 & 0.043 & 1.878 & 23.878 & 0.085 \\
\hline I-Section & $\beta=0.5$ & 0.230 & 12.230 & 0.019 & 0.788 & 22.788 & 0.036 \\
Girder & $\beta=1.0$ & 0.148 & 12.148 & 0.012 & 0.500 & 22.500 & 0.023 \\
\hline
\end{tabular}

$\operatorname{strain}\left(\varepsilon_{0}\right)$ and compensating $\operatorname{strain}\left(\varepsilon_{H}\right)$ at compressed edge of the web plate, is larger in the isolated web plate than that in the I-section girder panel (Table.1). This implies that the flange plate undertakes most part of compressive stress by bending. Therefore the stress level at compressed part of the isolated web plate is higher than those of I-section girder segment under the same forced bending $\operatorname{strain}\left(\varepsilon_{0}\right)($ Fig.3). In the analysis of the bending behavior of the isolated web plate of a curved plate girder, especially in the case where the bending is applied by forced displacement as employed here, it may be a more adequate to assume that the rotation of the edges is regarded as restrained in order to simulate the connection between the web and the flange plate.

(2) Distribution of out-of-plane displacement

As an example, the out-of-plane displacement(w) calculated for $\alpha=2 / 3$ and $\beta=0.5$ is shown in Fig. 4 by varying the width-thickness ratio $\lambda$. It may be reasonable that larger displacements appear for the larger width-thickness ratio $\lambda$ in the same magnitude of forced displacement and this tendency becomes more distinctive at the cross section 1/6 located in the distance of $a / 6$ from the loaded edge (refer to Fig. 1 about the notation of sections). Little difference of the maximum value between the out-of-plane displacements for the width-thickness ratio $\lambda=300$ and 500 is observed, but both values are fairly larger than that of $\lambda=150$. When the width-thickness ratio exceeds 300 , in the middle cross section of the panel (1/2), the displacement caused in the vicinity of the compressed flange reverses its direction. Especially, when $\lambda=500$, this reversal occurs at the low level of forced bending strain as $\varepsilon_{0}=0.0008$ (i.e. $\sigma_{0}=E \cdot \varepsilon_{0}=164 \mathrm{MPa}$ ), and this reversal makes the maximum displacement of the section $1 / 3$ becomes small. Other calculated results show that, at the large aspect ratio $\alpha$ such as 1.5 and the width-thickness ratio of the web $\lambda=300$, no reversal appears for $\beta=0.5$, but that when $\beta=1.0$, the reversal is observed at $\varepsilon_{0}=0.0012\left(\sigma_{0}=245 \mathrm{MPa}\right)$. This implies that the difference of the displacement mode may be caused by the aspect ratio.

The out-of-plane displacement at $\alpha=2 / 3$ and $\lambda=500$ is shown in Fig. 5 for various flange-web plate cross sectional area ratio $\beta$. The difference is rather small, but the following can be observed; larger-

$$
\text { W } \times 10^{-1} \mathrm{~cm}
$$

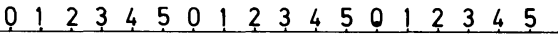

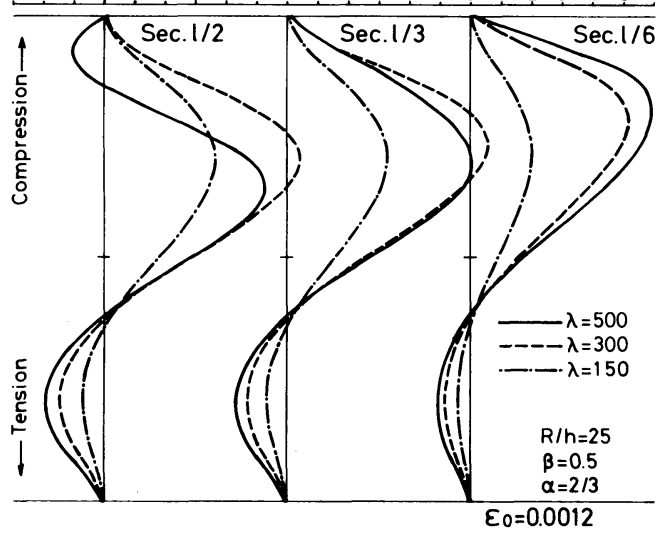

Fig. 4 Distribution of out-of-plane displacement (w) with parameter $\lambda$.

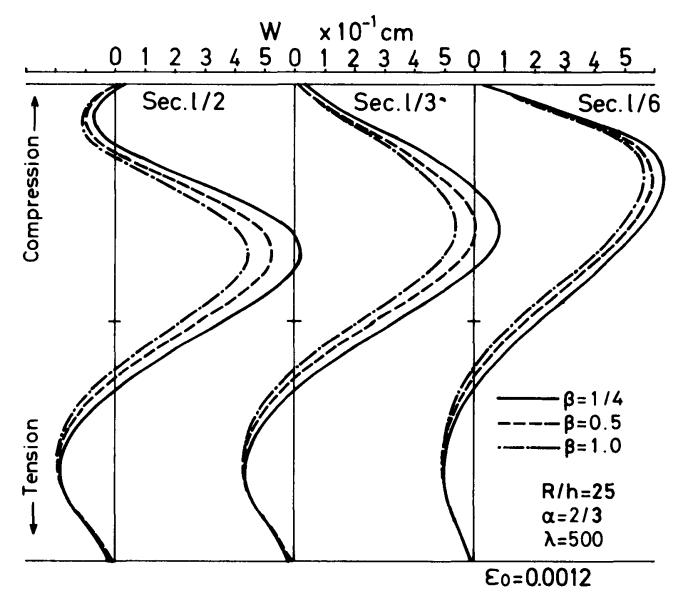

Fig. 5 Distribution of out-of-plane displacement $(w)$ with parameter $\beta$. 
displacement of the flange occurs for the I-girder panel with relatively small cross sectional area of the flange; the reversal of the direction of the displacement occurs even at the low loading level; the absolute value of the reversed displacements becomes larger for the cross sections with heavier flanges. This tendencies can be observed at $\lambda=300$, but not at $\lambda=150$.

\section{( 3 ) Distribution of in-plane bending stress}

A typical distribution of the in-plane bending stress is shown in Fig.6 when $\alpha=2 / 3$ and $\beta=0.5$. In the neighborhood of the neutral axis, the compressive stress of the web plate becomes very small compared with stress linearly distributed, especially for $\lambda=300$ and 500 , and this part of the web plate is called as an unresisting portion hereafter. In proportion to the width-thickness ratio the unresisting portion becomes significant. On the cross section $c$, the unresisting portion emerges even at the low stress level. When the width-thickness ratio $\lambda=150$, the unresisting portion is not noticeable below the stress level of $250 \mathrm{MPa}$ but becomes significant over the stress level of $420 \mathrm{MPa}$.

Another example of the in-plane bending stress is shown in Fig.7 as a function of the parameter of the sectional area ratio of flange to web plate $\beta$. It will be seen that the distribution is slightly influenced by this ratio. From Fig. 4 to Fig.7, following aspects are observed: the unresisting portion becomes clear as the out-of-plane bending displacements become large and thus there is a relationship between the out-of-plane displacement mode and the stress distribution. This tendency appears commonly in the isolated web plate as mentioned in section 3.(1).

\section{(4) Effective width of web plates}

Basler et al. ${ }^{1)}$ propose an effective compressive strip in web plate of straight plate girders to estimate the bending fiber stress in compression flanges. According to this proposal, the effective width of a web plate is calculated regarding the moment of compressed portion herein.

The primary moment of the linear compressive bending stress in the effective width about neutral axis is taken as equal to the primary moment of the nonlinear compressive bending stress about the axis when the extreme fiber stresses have equal value. Consequently the effective width $h_{e}$ can be defined here by the width of the strip of the cross section, as illustrated in Fig.8.

The relationships between the forced stress $\sigma_{0}$ produced by the forced bending strain $\varepsilon_{0}$ at the compression edge and the minimum value of the effective web width expressed nondimensionally by the web width are illustrated in Fig.9 with the former in abscissa and the latter in the ordinate. In the figure, these relationships are shown for various values of the parameter of the sectional area ratio of the flange to the

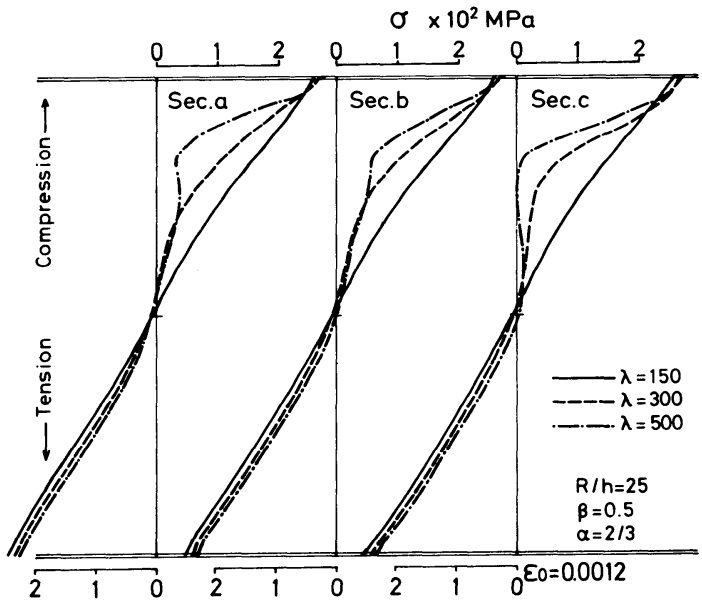

Fig. 6 Distribution of in-plane bending stress $(\sigma)$ with parameter $\beta$.

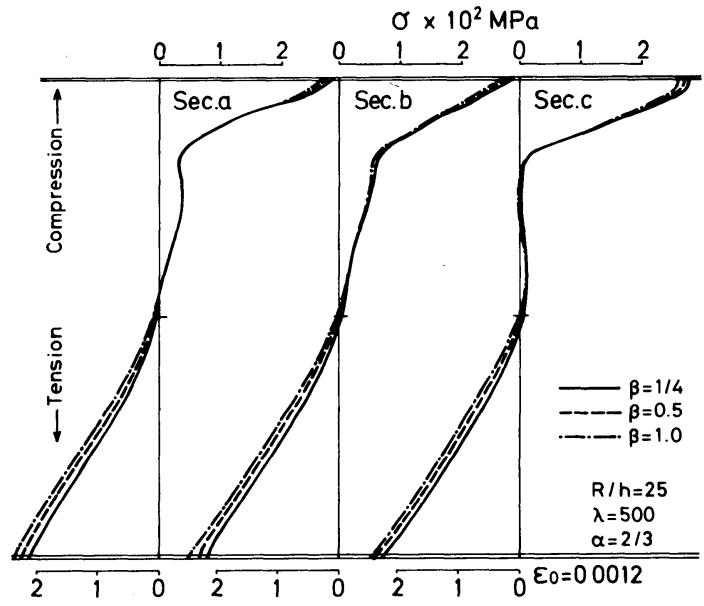

Fig. 7 Distribution of in-plane bending stress $(\sigma)$ with parameter $\beta$. 


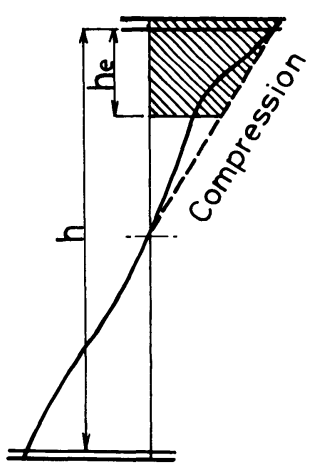

Fig. 8 Definition of effective web width.

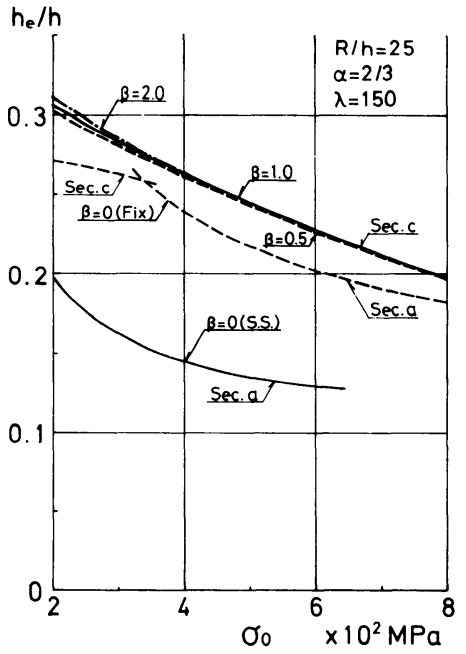

Fig. 9 Relationships between effective web width and stress level.

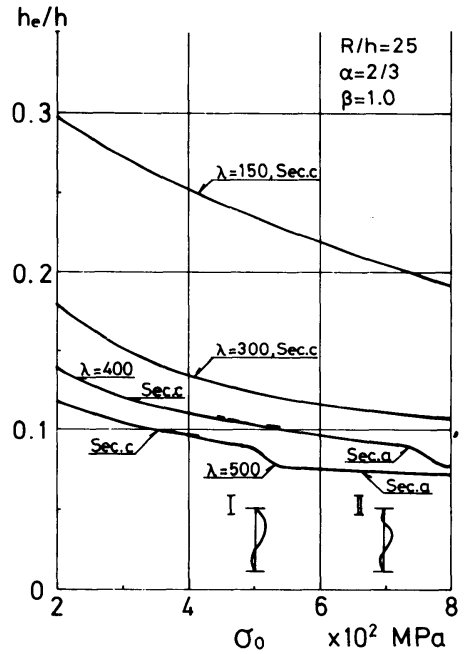

Fig. 10 Relationships between effective web width and stress level.

web plate $\beta$. The heavy lines with $\beta \neq 0$ show the results for the I-section girder panels and the thin lines with $\beta=0$ for the isolated web panels. The effective web width reduces as the stress level becomes high in all cases. The I-section panels are found to have larger effective web width than the isolated web panel. Especially the effective web width of the simply supported isolated web plate is estimated to be very small. This is considered to be caused by the small share of the web plate to bending, which does not make the stress distribution of the web plate severe, and also affected by the small amount of the significant compensating strain mentioned in the previous section, which does not decrease the effective web width so much. The variations of the effective web width are independent of the size of flange section in all cases including the case of $\lambda=150$ as is seen in the figure. The indication of section $a, b$ or $c$ in the figure means that the minimum value of the effective web width obtained in that section.

Relationships between the effective web width and the stress level are shown in Fig.10 with various values of the width-sthickness ratio $\lambda$. Smaller effective web width is obtained in large $\lambda$, especially in $\lambda \geqq 300$. The dislocations in the lines of $\lambda=400$ and 500 indicate the change of out-of-plane displacement mode from type I to type II shown in the figure. In small width-thickness ratio and low stress level, the minimum value of the effective web width is obtained in the section $c$, but in larger width-thickness ratio and higher stress level it moves to the section a.

Table 2 shows the nondimensional effective web width for the I-section girders used various grade of steel, determined by taking the maximum compressive stress as the nominal yield point of it in a certain

Table 2 Non-dimensional effective web width $\left(h_{e} / h\right)$

upper line for $\operatorname{SS} 41\left(\sigma_{y}=235.2 \mathrm{MPa}\right)$, middle line for $\operatorname{SS} 50 \mathrm{Y}\left(\sigma_{y}=352.8 \mathrm{MPa}\right)$,

Lower line for $\operatorname{SM} 58\left(\sigma_{\mathrm{y}}=450.8 \mathrm{MPa}\right)$.

\begin{tabular}{|c|c|c|c|c|c|c|c|c|c|c|c|}
\hline \multirow{2}{*}{\multicolumn{2}{|c|}{$\begin{array}{l}\text { Aspect Ratio }(\alpha) \\
\text { Width-Thickness Ratio }(\lambda)\end{array}$}} & \multicolumn{3}{|c|}{0.5} & \multicolumn{4}{|c|}{$2 / 3$} & \multirow{2}{*}{\multicolumn{2}{|c|}{$\frac{\text { Aspect Ratio }(\alpha)}{\text { Width-Thickness Ratio }(\lambda)}$}} & $2 / 3$ \\
\hline & & 150 & 300 & 500 & 150 & 300 & 400 & 500 & & & 150 \\
\hline \multirow{4}{*}{ I-Section Girder } & $\beta=0.5$ & & & & $\begin{array}{l}0.294 \\
0.269 \\
0.251\end{array}$ & $\begin{array}{l}0.167 \\
0.140 \\
0.127\end{array}$ & & $\begin{array}{l}0.111 \\
0.098 \\
0.090\end{array}$ & \multirow{4}{*}{$\begin{array}{c}\text { Isolated } \\
\text { Web } \\
\text { Plate }\end{array}$} & $\begin{array}{l}\text { Upper \& } \\
\text { Lower Edges } \\
\text { Simply Supported }\end{array}$ & $\begin{array}{l}0.296 \\
0.253 \\
0.226\end{array}$ \\
\hline & \multirow{3}{*}{$\beta=1.0$} & 0.288 & 0.156 & 0.106 & 0.297 & 0.171 & 0.130 & 0.111 & & Upper \& & 0.279 \\
\hline & & 0.248 & 0.143 & 0.090 & 0.271 & 0.142 & 0.114 & 0.100 & & Lower Edges & 0.250 \\
\hline & & 0.227 & 0.128 & 0.083 & 0.253 & 0.129 & 0.106 & 0.091 & & Restrained & 0.238 \\
\hline
\end{tabular}


combinations of parameters. The effective web width is much influenced by the width-thickness ratio but merely influenced by the aspect ratio $\alpha$ and the influence of the sectional area ratio of a flange to a web plate $\beta$ is negligibly small.

\section{(5) Resisting bending moment of girder}

In curved plate girders of comparatively small radius of curvature as employed in this analysis, the distribution of in-plane bending stress indicates nonlinearity even in the first-order elastic analysis and therefore the resisting bending moment of a curved plate girder shows smaller value than that of a straight plate girder under the assumption of the linearly distributed in-plane bending stress. Here, the non-dimensional resisting bending moment caused by the nonlinearity of stress is expressed by the ratio of the bending moment $M$ calculated from the nonlinealy distributed in-plane bending stress of a curved girder to the moment $M_{0}$ from linear distribution of a straight girder.

Relationships between the nondimensional resisting bending moment and the stress level at the compressive flange edge expressed by $\sigma$ is shown in Fig.11 for different combination of parameters such as the width-thickness ratio $\lambda$, the sectional area ratio of the flange to the web plate $\beta$ and the aspect ratio of the web plate $\alpha$. The resisting bending moment decreases as the stress level is elevated. This decrease becomes more significant with larger width-thickness ratio and/or smaller sectional area ratio. The resisting bending moment becomes maximum when $\alpha=2 / 3$, and decreases for larger or smaller value of $\alpha$ than $2 / 3$. While the resisting bending moment is slightly influenced by the aspect ratio of the web plate, it is considerably influenced by the width-thickness ratio and sectional area ratio. In the figure, the plotted value against $\sigma=0$ is obtained by the first-order elastic analyses.

The resisting bending moment in the case of $\alpha=2 / 3, \beta=0.5$ and 1.0 is shoen in Fig.12 for different the width-thickness ratio. The resisting bending moment are more sensitive to $\lambda$ for smaller $\beta$. Namely, at the same width-thickness ratio, the resisting bending moment becomes always smaller at smaller $\beta$, and the difference caused by $\lambda$ becomes prominent in the higher stress level.

The resisting bending moments are also obtained by equating the maximum compressive stress $\sigma$ to the nominal yield stress of steels, and are given in Table 3. When $\lambda=150$ and $\beta \geqq 1.0$, the influence of $\beta$ on the resisting bending moment is not perceivable. For smaller value of $\beta$ as 0.5 , the resisting bending moment decreases throughout the analyzed range, especially in high stress level. For the large width-thickness

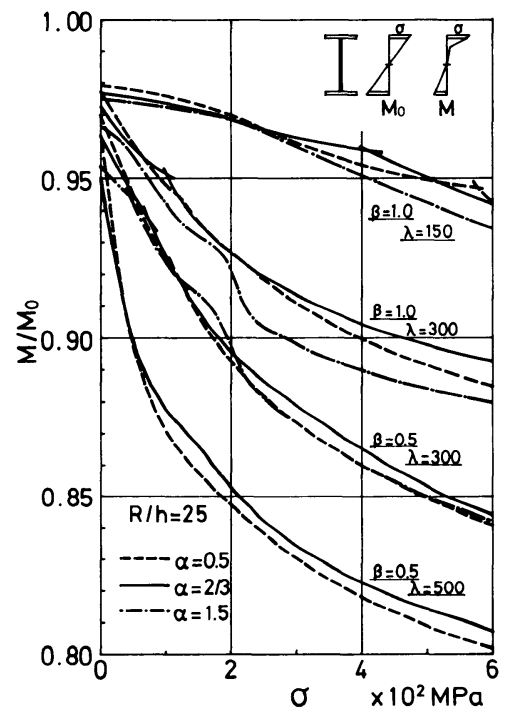

Fig. 11 Relationships between resisting moment and stress level.

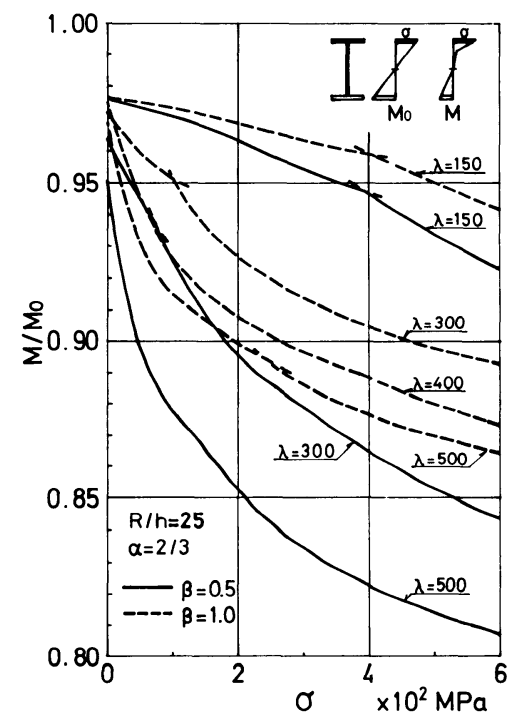

Fig. 12 Relationships between resisting moment fna stress level. 
Table 3 Resisting Bending moment $\left(M / M_{0}\right)$

upper line for $\operatorname{SS4} 1\left(\sigma_{y}=235.2 \mathrm{MPa}\right)$, middle line for $\operatorname{SS} 50 \mathrm{Y}\left(\sigma_{\mathrm{y}}=352.8 \mathrm{MPa}\right)$,

Lower line for $\operatorname{SM} 58\left(\sigma_{y}=450.8 \mathrm{MPa}\right)$.

\begin{tabular}{|c|c|c|c|c|c|c|c|c|c|}
\hline Aspect Ratio $(\alpha)$ & \multicolumn{3}{|c|}{0.5} & \multicolumn{4}{|c|}{$2 / 3$} & \multicolumn{2}{|c|}{1.5} \\
\hline Width-Thickness Ratio $(\lambda)$ & 150 & 300 & 500 & 150 & 300 & 400 & 500 & 150 & 300 \\
\hline$\beta=1 / 4$ & & & $\begin{array}{l}0.772 \\
0.748 \\
0.732\end{array}$ & & & & $\begin{array}{l}0.774 \\
0.748 \\
0.735\end{array}$ & & \\
\hline$\beta=0.5$ & & $\begin{array}{l}0.884 \\
0.865 \\
0.854\end{array}$ & $\begin{array}{l}0.845 \\
0.827 \\
0.818\end{array}$ & $\begin{array}{l}0.960 \\
0.950 \\
0.940\end{array}$ & $\begin{array}{l}0.889 \\
0.871 \\
0.858\end{array}$ & & $\begin{array}{l}0.841 \\
0.823 \\
0.812\end{array}$ & & $\begin{array}{l}0.883 \\
0.865 \\
0.854\end{array}$ \\
\hline$\beta=1.0$ & $\begin{array}{l}0.960 \\
0.961 \\
0.955\end{array}$ & $\begin{array}{l}0.921 \\
0.904 \\
0.895\end{array}$ & $\begin{array}{l}0.840 \\
0.823 \\
0.812\end{array}$ & $\begin{array}{l}0.967 \\
0.957 \\
0.952\end{array}$ & $\begin{array}{l}0.921 \\
0.908 \\
0.901\end{array}$ & $\begin{array}{l}0.903 \\
0.892 \\
0.884\end{array}$ & $\begin{array}{l}0.894 \\
0.881 \\
0.873\end{array}$ & $\begin{array}{l}0.966 \\
0.955 \\
0.947\end{array}$ & $\begin{array}{l}0.905 \\
0.893 \\
0.886\end{array}$ \\
\hline
\end{tabular}

ratio $\lambda$, the resisting bending moment is sensitive to the sectional area ratio $\beta$, and decreases considerably in high stress level.

\section{(6) Vertical buckling of flange plates-Spring effect of web plates}

When lateral buckling and torsional buckling of a flange plate are prevented such that the plate girder can show an enough capacity to resist the bending moment, the distance between the upper and lower flanges can be held constant because of sufficient rigidty of the web plate. Basler et al. ${ }^{11}$ define vertical buckling of flange plates by treating the buckling strength of web plate as a column buckling strength subjected to the vertical compressive stress in the web due to the vertical component of bending stresses in flanges. But as pointed out in Ref.5), when a straight plate girder with a certain amount of initial deflection or a curved plate girder which has inherent initial curvatures is considered, the out-of-plane displacements of the web plate under bending grow so large with the increase of the stress level that the vertical displacement of the upper edge of the web plate exists definitely. Therefore, Basler's simple model may not enough explain this phenomenon.

At first, regarding a compression flange as a column which is supported vertically by the spring action of web plates, vertical buckling stress of a flange platae will be discussed here.

The method to determine the spring constant in the vertical direction is as follows. Very small amount of uniformly distributed vertical $\operatorname{load}(q)$ is applied normal to the compression edge of the finitely buckled web plate isolated from an I-girder panel, and the vertical displacement $(\delta)$ of the edge under bending is calculated. Thus the spring constant $\left(\gamma\left[\mathrm{N} / \mathrm{cm}^{2}\right]\right)$ of the web plate is given by the ratio of $q$ to $\delta$. The minimum value of the spring constant is obtained in the section $1 / 2$ of simply supported web plates and in the section $1 / 6$ of restrained one, but no definite difference between both cases is recognized. A discussion will be done in the restrained case.

Relationships between the reciprocal value of the spring constant $(1 / \gamma)$ and the stress level expressed by the forced bending stress $\sigma_{0}$ are shown in Fig.13. The spring constant is not constant over the length of the web plate. For example, a negative spring constant is evaluated in the section 1/6. But the value in the section $1 / 3$ is chosen here, and its effect is examined.

The smaller the aspect ratio $\alpha$ becomes, the larger the spring constant becomes. The spring does not vary so much with the stress level below the yield stress of steels. When the width-thickness ratio $\lambda=240$, the maximum value of the spring constant $\gamma$ is $10.9 \mathrm{kPa}$ for the aspect ratio $\alpha=2 / 3$ and $\gamma=6.6 \mathrm{kPa}$ for $\alpha=1.0$. These values do not yield so higher buckling stress $\sigma_{c r}$ to flanges which are supported by the springs than that of a hinge-ended isolated flange column, if the cross sectional area is kept same. When $\beta=1.0$, namely the bending rigidity of the flange plate is relatively large, $\sigma_{c r}$ of a flange supported by the springs is 86.9 $\mathrm{MPa}$ for $\alpha=2 / 3$ and 39.2 MPa for $\alpha=1.0$. Therefore, these buckling stresses are not so high that the flange plate should buckle vertically in rather low stress level. 
But in this numerical analysis, the reduction of the bending resisting capacity due to vertical buckling of flanges is not observed. As described in 3.(4) and (5), both the nondimensional effective web width $h_{e} / h$ and the resisting bending moment $M / M_{0}$ of plate girders do not show any abrupt change in their value, but decrease continuously with the elevation of stress. This may be explained by the following reasons: the spring constant is not constant over the panel length, so that the equivalent buckling length is shorter than the length of the panel, and the spring action of a web is sustained even in high stress level as seen in Fig.13. Consequently the distance between the upper and lower flanges does not change rapidly. Judging from the calculated results, the flanges of curved plate girders seem to be supported quite stably in the vertical direction by the buckled web plate, even if the width-thickness ratio were considerable large. Therefore it may be concluded that vertical buckling of a flange plate occurs when the web plate yields. The failure due to the vertical movement of flange plates will be determined by the yielding of the buckled web plates.

(7) Additional stress in flange plate

a) Torsional moment: The torsional moment of compressive flanges is smaller for smaller width-thickness ratio of the web plate. And the moment grows larger for larger cross sectional area of the flange plate, but the torsional stress due to this moment is at most 3.9 MPa. Therefore, no attention is paid on this torsional moment for designing a girder.

b) Shearing stress in the direction of the radius of curvature: Because of the curvature of a curved plate girder, the fiber stresses change their direction along the circumference. As a result of these fiber stresses, the shearing stress in the direction of the radius of curvature is generated at the connection between the compressive flange and the web plate. This shearing force is expressed by $\tau$ or $k=\tau / \tau_{0}$ in the non-dimensional form, where $\tau_{0}$ is calculated by the elementary theory as $\tau_{0}=H / R=$ $M / h / R$. Fig.14 shows an example of the relationships between $k$ and maximum bending stress $\sigma$ of the compressive flange. The non-dimensional shearing force $k$ becomes larger in the section $\mathrm{c}$ near the loaded edge, and smaller in the section a near to the center of the panel. And $k$ becomes a little larger with higher stress level in the section $c$, but has little variety with stress level in the section $a$. The value of $k$ is little influenced by width-thickness ratio $\lambda$, and this is a contradiction to our previous conclusion of Ref.5), which states that the shearing force directed to the radius is very sensitive to the width-thickness ratio and the stress level. The value $k$ in the section $\mathrm{c}$ generally grows larger with the smaller width-thickness ratio, and does not change with varying of the falue $\beta$ in the range of $\beta \geqq 1.0$. The $k$ value is more sensitive to the stress level when $\beta$ is small. In the case of small $\beta$ and large $\lambda, k$ is about 20 .

c) Stress due to bending about the vertical axis : In addition to the girder bending stress, stresses due to the moment about vertical axis are produced so that the compressive stress of the flange becomes larger at the inside edge and smaller at the outside edge. The stress gradient $\phi$ in the flange defined by the

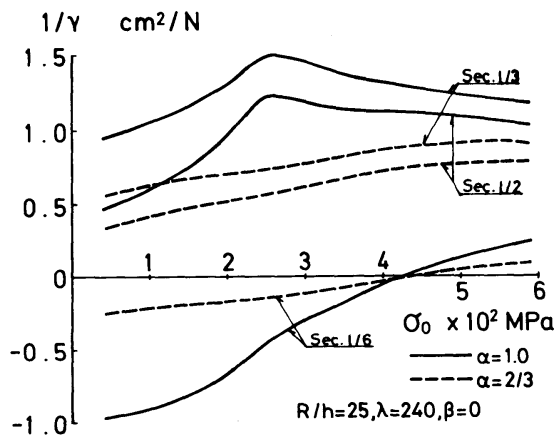

Fig. 13 Relationships between spring constant (in reciprocal) and stress level.

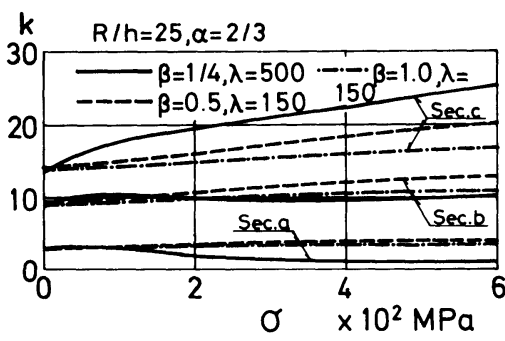

Fig. 14 Shearing force to the direction of curvature. 


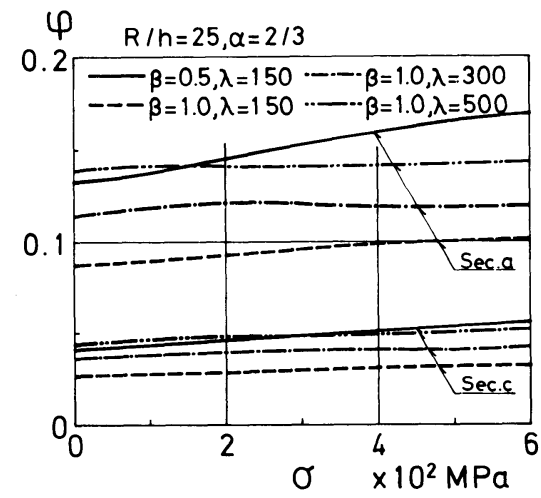

Fig. 15 Stress gradient of compressed flange.
Table 4 Stress Gradient of Compressed Flange $(\phi)$ upper line for $\operatorname{SS41}\left(\sigma_{y}=235.2 \mathrm{MPa}\right)$, middle line for SS50Y $\left(\sigma_{y}=352.8 \mathrm{MPa}\right)$, Lower line for SM58 $\left(\sigma_{y}=450.8 \mathrm{MPa}\right)$.

\begin{tabular}{l|c|c|c|c}
\hline Aspect Ratio $(\alpha)$ & \multicolumn{4}{|c}{$2 / 3$} \\
\hline $\begin{array}{l}\text { Width-Thickness Ratio } \\
(\lambda)\end{array}$ & 150 & 300 & 400 & 500 \\
\hline$\beta=1 / 4$ & & & & 0.376 \\
\hline & 0.148 & 0.210 & & 0.210 \\
$\beta=0.5$ & 0.157 & 0.209 & & 0.210 \\
& 0.163 & 0.208 & & 0.213 \\
\hline & 0.093 & 0.121 & 0.144 & 0.140 \\
$\beta=1.0$ & 0.097 & 0.120 & 0.143 & 0.141 \\
& 0.099 & 0.119 & 0.143 & 0.141 \\
\hline
\end{tabular}

following expression is developed.

$$
\phi=\left(\sigma_{1}-\sigma_{2}\right) / \sigma_{1}
$$

where $\sigma_{1}$ and $\sigma_{2}$ are the stresses at the inside and outside of flange respectively

An example of the relationships between the stress gradient and the stress level in each section is given in Fig.15. The stress gradient shows larger value in the section a and smaller value in the section $c$. In the range where the width-thickness ratio exceeds a certain value, the stress gradient is not influenced by $\lambda$. But, when $\lambda$ is small, it is relatively sensitive to $\lambda$. The stress gradient grows larger as the stress level becomes higher, but in the case of $\beta>1.0$ and $\lambda>300$, the influence of the stress level is not significant. Table 4 shows the stress gradient at various stress levels which are corresponding to the each yield stress of structural steels for $\alpha=2 / 3$. The stress gradient is larger in smaller $\beta$, and in the extreme case it becomes larger than 0.4 when $\lambda=500$ and $\beta=1 / 4$. Therefore, attention must be paid at use of the curved plate girder with small size of a compressive flange plate. It must be noted that the collapse of the whole structure of curved I-section girders is considered to be induced by the failure of a compressive flange.

\section{CONCLUSION OF REMARKS}

In this paper, an elastic finite displacement analysis of the behavior of curved plate girders under bending is carried out by using the finite element technique. Especially, attention is paid to the interactions between the web plate and the flange plate and to the influence of the boundary condition at the loaded edges. From the analyzed results, the following conclusions are drawn:

(1) When the web plate panel is isolated from a curved I-section plate girder as a sub-structure to analyze the out-of-plane displacement and the in-plane bending stress distribution, it seems to be reasonable to assume that the top and the bottom edges are supported free to the vertical direction and restrained against the rotation about the circumference axis rather than to assume the simple support to the vertical direction. The calculated results show that the former condition makes the web plate panel simulate more adequately the behavior of the I-girder web panel subjected to bending.

(2) The out-of-plane displacement becomes very large when the width-thickness ratio of the web plate exceeds 300 . When the aspect ratio is large, the reversal of the direction of the displacement in the middle section of the panel occurs. In the process of the incremental loading, this reversal becomes significant in the panel with large size of the flange cross section.

(3) The nonlinearity of the in-plane bending stress distribution in a web plate is more significant with large width-thickness ratio, but it is little influenced by the size of the flange plate. A strong interaction between the out-of-plane displacement mode and the in-plane bending stress distribution mode is observed.

(4) The effective web width defined in this paper is a little larger in the I-section girder panels than in the isolated web plate panels. This effective web width is significantly influenced by the width-thickness 
ratio of web plate, and is affected by the size of the flange plate. It becomes larger for smaller width-thickness ratio. In a curved plate girder built up by conventional steels, the effective web width ranges between about 0.23 and 0.25 when the width-thickness ratio is 150 .

(5) The resisting bending moment of a curved plate girder is a little larger when the aspect ratio of the web plate is $2 / 3$ than when it is 0.5 or 1.5 . But the resisting bending moment is slightly affected by the aspect ratio, and is sensitive to the width-thickness ratio of the web plate and the cross sectional area ratio of the flange plate to the web plate. From the beam theory, it is commonly stated that the most economical flange-web cross section ratio is 0.5 , but, in this analysis, the resisting bending moment becomes small when the ratio is smaller than 0.5 . This tendency becomes more significant in large width-thickness ratio.

(6) If the web plate of a curved plate girder under bending is stiffened by rigid transverse stiffeners and if the aspect ratio of the web plate is less than 1.0, the compression flange does not buckle elastically in the vertical direction. The vertical buckling of a flange plate depends on yielding of the web plate, since it is considered to occur when the web plate loses the ability to support the flange plate elastically.

(7) The stress gradient in the flange plate of a curved plate girder is produced by bending about the vertical axis, and the stresses become larger in the smaller size of the cross section of the flange. Therefore careful consideration should be taken in designing.

\section{REFERENCES}

1) Basler, K. and Thurlimann, B. : Strength of plate girders in bending, Proc. of ASCE, Vol.87, No.ST6, pp.153 181, Aug. 1961.

2) Hasegawa, A., Horiguchi, T. and Nishino, F.: A consideration on ultimate strength of plate girders (Part l, Part 2), Bridges and Foundations, Vol.11, No.4, No.5, pp.25 32, pp.8 12, April, May, 1977 (in Japanese).

3) Hasegawa, A., Wada, K. and Nishino, F. : Tests on transversely stiffened plate girders in bending, Proc. of JSCE, No.305, pp.27 37, Jan. 1981 (in Japanese).

4) Maegawa, K. and Yoshida, H. : Ultimate strength analysis of curved I-beams by transfer matrix method, Proc. of JSCE, No.312, pp.27 37, Aug. 1981 (in Japanese).

5) Kuranishi, S. and Hiwatashi, S. : Elastic behavior of web plates of curved plate girders in bending, Proc. of JSCE, No.315, pp.1 11, Nov. 1981 (in Japanese).

6) Kuranishi, S. and Hiwatashi, S. : Non-linear behavior of elastic web plates of curved girder under bending moment, Proc. of The 3rd Int. Coll. on Stability of Metal Struc. at Paris (Nov. 1983), pp.305 312.

7) Nakai, H. and Kotoguchi, H. : A study on lateral buckling strength and design aid for horizontally curved I-girder bridges, Proc. of JSCE, No.339, pp.195 204, Nov. 1983.

8) Nakai, H., Kitada, T. and Ohminami, R. : Experimental study on bending strength of web plate of horizontally curved girder bridges, Proc. of JSCE, No.340, pp.19 28, Dec. 1983 (in Japanese).

9) Brebbia, C. and Connor, J. : Geometrically nonlinear finite-element analysis, Proc. of ASCE, Vol.95, No.EM2, pp.463 483, April, 1967.

10) Timoshenko, S. : Theory of Elastic Stability, McGraw Hill (1936). 